\title{
Lung function in HIV-infected children and adolescents
}

\author{
Leah N. Githinji ${ }^{*} \mathbb{D}$, Diane M. Gray and Heather J. Zar
}

\begin{abstract}
Background: The advent of antiretroviral therapy has led to the improved survival of human immunodeficiency virus (HIV)-infected children to adulthood and to HIV becoming a chronic disease in older children and adolescents. Chronic lung disease is common among HIV-infected adolescents. Lung function measurement may help to delineate the spectrum, pathophysiology and guide therapy for HIV-related chronic lung disease.

Aim: The aim of this study was to review the available data on the spectrum and determinants of lung function abnormalities and the impact of antiretroviral therapy on lung function in perinatally HIV-infected children and adolescents.
\end{abstract}

Methods: Electronic databases "PUBMED", "African wide" and "CINAHL" via EBSCO Host, using the MeSH terms "Respiratory function" AND "HIV" OR "Acquired Immunodeficiency Syndrome" AND "Children" OR "Adolescents", were searched for relevant articles on lung function in HIV-infected children and adolescents. The search was limited to English language articles published between January 1984 and September 2017.

Results: Eighteen articles were identified, which included studies from Africa, the United States of America (USA) and Italy, representing $2051 \mathrm{HIV}$-infected children and adolescents, 68\% on antiretroviral therapy, aged from 50 days to 24 years. Lung function abnormalities showed HIV-infected participants had increased irreversible lower airway expiratory obstruction and reduced functional aerobic impairment on exercise, compared to HIV-uninfected participants. Mosaic attenuation, extent of bronchiectasis, history of previous pulmonary tuberculosis or previous lower respiratory tract infection and cough for more than 1 month were associated with low lung function. Pulmonary function tests in children established on antiretroviral therapy did not show aerobic impairment and had less severe airway obstruction.

Conclusion: There is increasing evidence that HIV-infected children and adolescents have high prevalence of lung function impairment, predominantly irreversible lower airway obstruction and reduced aerobic function.

Keywords: HIV, Lung function, Children, Adolescents

\section{Background}

Improved survival of perinatally human immunodeficiency virus (HIV)-infected children to adolescence has occurred with the scale-up of pediatric antiretroviral therapy (ART) and prevention of mother-to-child transmission (PMTCT) programs. This has led to a large cohort of youth living with vertically transmitted HIV in sub-Saharan Africa [1]. Of the 2.3 million children living with HIV globally, $43 \%$ are on ART [2,3]. In 2016, 7 million people were reported to be living with HIV in

\footnotetext{
* Correspondence: gthlea001@myuct.ac.za

Department of Paediatrics and Child Health, Red Cross War Memorial Children's Hospital and MRC Research Unit on Child and Adolescent Health, University of Cape Town, Rondebosch, Klipfontein Road 7700, Cape Town, South Africa
}

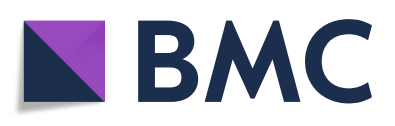

(c) The Author(s). 2018 Open Access This article is distributed under the terms of the Creative Commons Attribution 4.0 International License (http://creativecommons.org/licenses/by/4.0/), which permits unrestricted use, distribution, and reproduction in any medium, provided you give appropriate credit to the original author(s) and the source, provide a link to the Creative Commons license, and indicate if changes were made. The Creative Commons Public Domain Dedication waiver (http://creativecommons.org/publicdomain/zero/1.0/) applies to the data made available in this article, unless otherwise stated. 19 years old [2].

HIV-related chronic lung disease (CLD) is a major cause of morbidity and mortality $[4,5]$. In the post-ART era, the spectrum of CLD has changed from lymphocytic interstitial pneumonitis (LIP) being most predominant to bronchiolitis obliterans and bronchiectasis being more prevalent patterns $[5,6]$. The spectrum of chronic lung disease in HIV infection has broad clinical phenotypes. For example, bronchiolitis obliterans may present as an obstructive pattern on spirometry [5], while chronic Pneumocystis jirovecii pneumonia (PCP), pulmonary tuberculosis (TB), bronchiectasis or LIP have a restrictive or mixed pattern spirometry. Interstitial pneumonitis, 
LIP and PCP are likely to lead to a reduced diffusion capacity for carbon monoxide (DLCO).

Comprehensive lung function measures are therefore needed to delineate the spectrum of CLD, monitor progression, and guide therapy and treatment response. These include measurements of lung capacities and flow, such as spirometry and bronchodilator response testing; measurement of lung volumes with plethysmography; measurement of resistance and compliance with tests such as the forced oscillation technique (FOT), interrupter technique or single-breath occlusion technique; measurement of gas diffusion with single-breath carbon monoxide lung diffusion test to assess alveolar-capillary membrane function; measurement of ventilation distribution with multiple breath nitrogen wash-out test (MBW); and cardiopulmonary functional assessment with the six-minute walk test (6MWT) and exercise (treadmill) testing.

The aim of this study was to review the available data on the spectrum and determinants of lung function abnormalities in perinatally HIV-infected children and adolescents.

\section{Methods}

A review of published literature was performed by searching "PUBMED", "African wide" and "CINAHL" via EBSCO Host using the MeSH terms "Respiratory function" AND "HIV" OR "Acquired Immunodeficiency Syndrome" AND "Children" OR "Adolescents"; full search terms are shown in Table 1. The search was limited to English language articles with a publication date between January 1984 and September 2017. Articles involving infants, children, adolescents or youth, HIV-infected or exposed, and lung function testing were included. Articles on adult studies or healthy populations were excluded. Where full articles could not be retrieved on Endnote, the full article was requested from the corresponding author by email. In addition to database searches, other relevant references from previous original articles were searched manually through Google Scholar. Data regarding patient characteristics, lung function test used and outcome were abstracted and summarized in table format.

\section{Results}

The process of the literature search is shown in Fig. 1. After combining all the search terms, 146 articles were found; 8 additional articles were obtained by a manual search, (Fig. 1). One hundred and thirty-six studies were excluded because they were unrelated to lung function, or were not related to the population of interest, or only a conference abstract was available. Eighteen full-text articles were found and included in this review (Table 2). All included studies were published between July 1997 and September 2017. Of the 18 included studies, 11 were from Africa, 6 from the United States of America (USA) and 1 from Italy. Three studies focused on infants (two of which also included HIV-exposed uninfected infants) [7-9], two focused on children $<8$ years $[10,11]$ and 13 focused on adolescents and youth (9-24 years), (Table 2). Eleven studies had a comparator group (control) (Table 2). All the HIV-infected participants were perinatally infected.

Baseline characteristics of participants differed among studies with median age ranging from 50 days to 24 years. The number of participants in each study ranged from 100 to 600 , with a total of 2051 HIV-infected participants pooled from all studies. Severity of disease differed; Ferrand et al. [6] reported 66\% had chronic cough, McHugh et al. [1] reported 54\% had chronic cough. Githinji et al. [12] reported 3.5\% had clubbing while Mwalukomo [13] reported 22\% with digital clubbing.

Participants were reported to have been on ART in 75\% of the studies (Table 2). The duration of ART was reported in 5 studies and ranged from 2 to 8 years [12, 1416]. In 3 studies, no participant was on ART (Table 2); 2 of these studies took place in sub-Saharan Africa [1, 17] and 1 in Italy in the pre-ART era [11].

Lung function measures reported were spirometry with bronchodilator response testing and exercise testing (with treadmill or incremental shuttle walk test or $6 \mathrm{MWT})$. One study included comprehensive lung function testing including FOT and MBW tests [12].

Spirometry testing was standardized in all studies as per American Thoracic Society (ATS)/European Respiratory Society (ERS) criteria [18]. The definition of restrictive pattern spirometry varied across studies with most reporting reduced forced vital capacity (FVC) as a spirometry pattern. The definition of obstructive pattern also varied across studies, with some studies using the lower limit of normal of forced expiratory volume in $1 \mathrm{~s} /$ forced vital capacity $\left(\mathrm{FEV}_{1} / \mathrm{FVC}\right)$, as per the global lung initiative reference [19] and others using $\mathrm{FEV}_{1} / \mathrm{FVC}<80 \%$. Shearer et al. [20] had broad inclusion criteria of obstructive spirometry pattern including $\mathrm{FEF}_{25-75}<65 \%$ or $\mathrm{FEV}_{1} / \mathrm{FVC}<80 \%$.

Assessment and definition of bronchodilator responsiveness varied among the studies. Criteria for bronchodilator responsiveness (BDR) in most studies was change in $\mathrm{FEV}_{1}>12 \%$. Shearer et al. [20] used albuterol and a change of $\geq 10 \%$ in $\mathrm{FEV}_{1}$. Three studies used $2.5 \mathrm{mg}$ nebulized salbutamol $[1,13,16]$ while the rest used $400 \mu \mathrm{g}$ inhaled salbutamol.

Of the 10 studies reporting spirometry findings (Table 2), 9 reported obstructive spirometry pattern, 6 of which demonstrated low rates of bronchodilator reversibility. In 5 studies with a comparator group, this rate of irreversible obstruction spirometry was higher in the HIV-infected. Rylance et al. [16] reported 11 (35\%) out of 31 


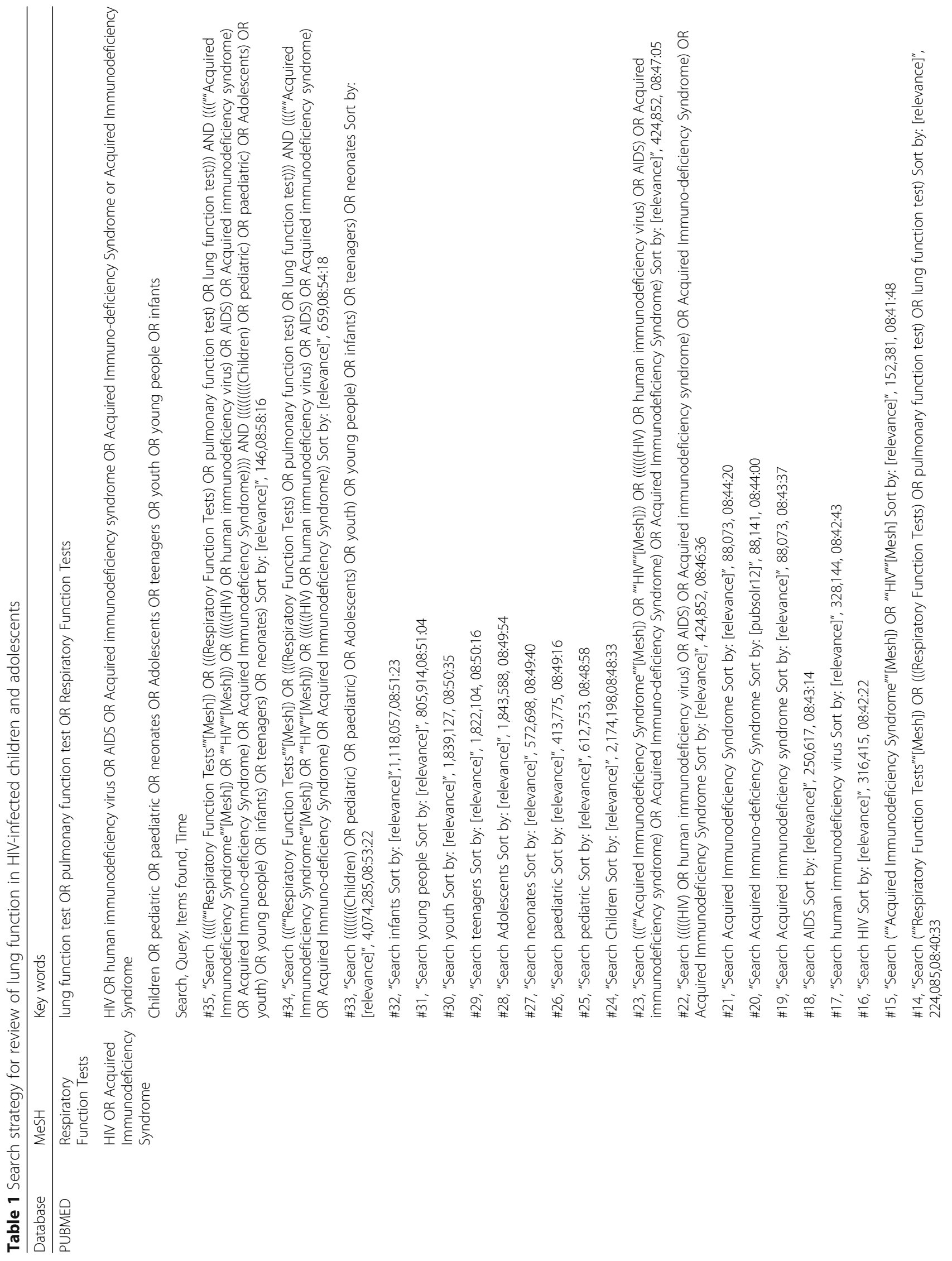




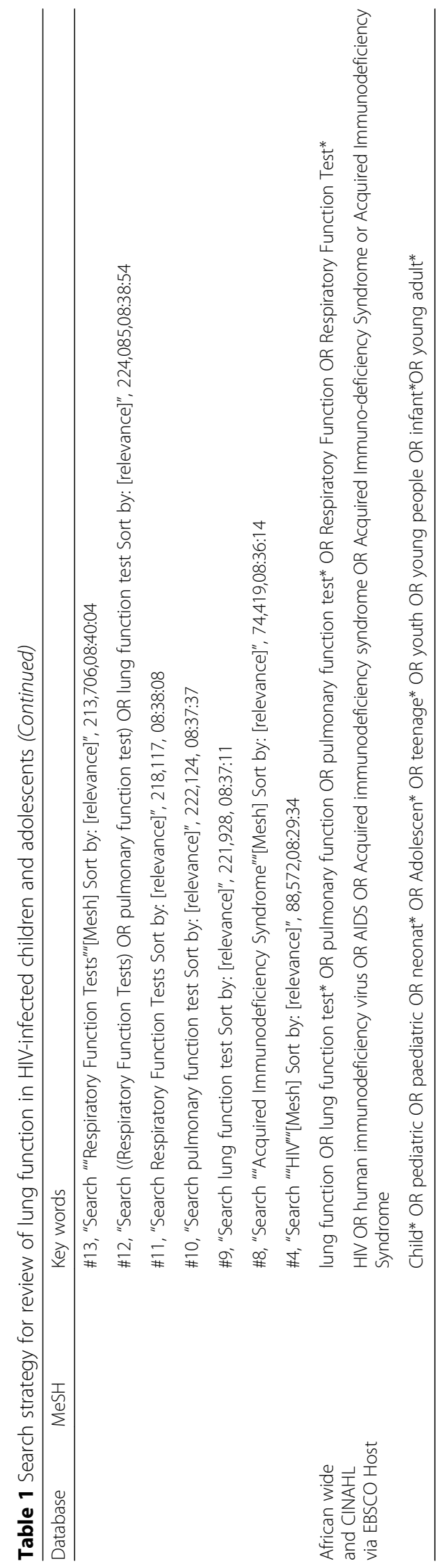




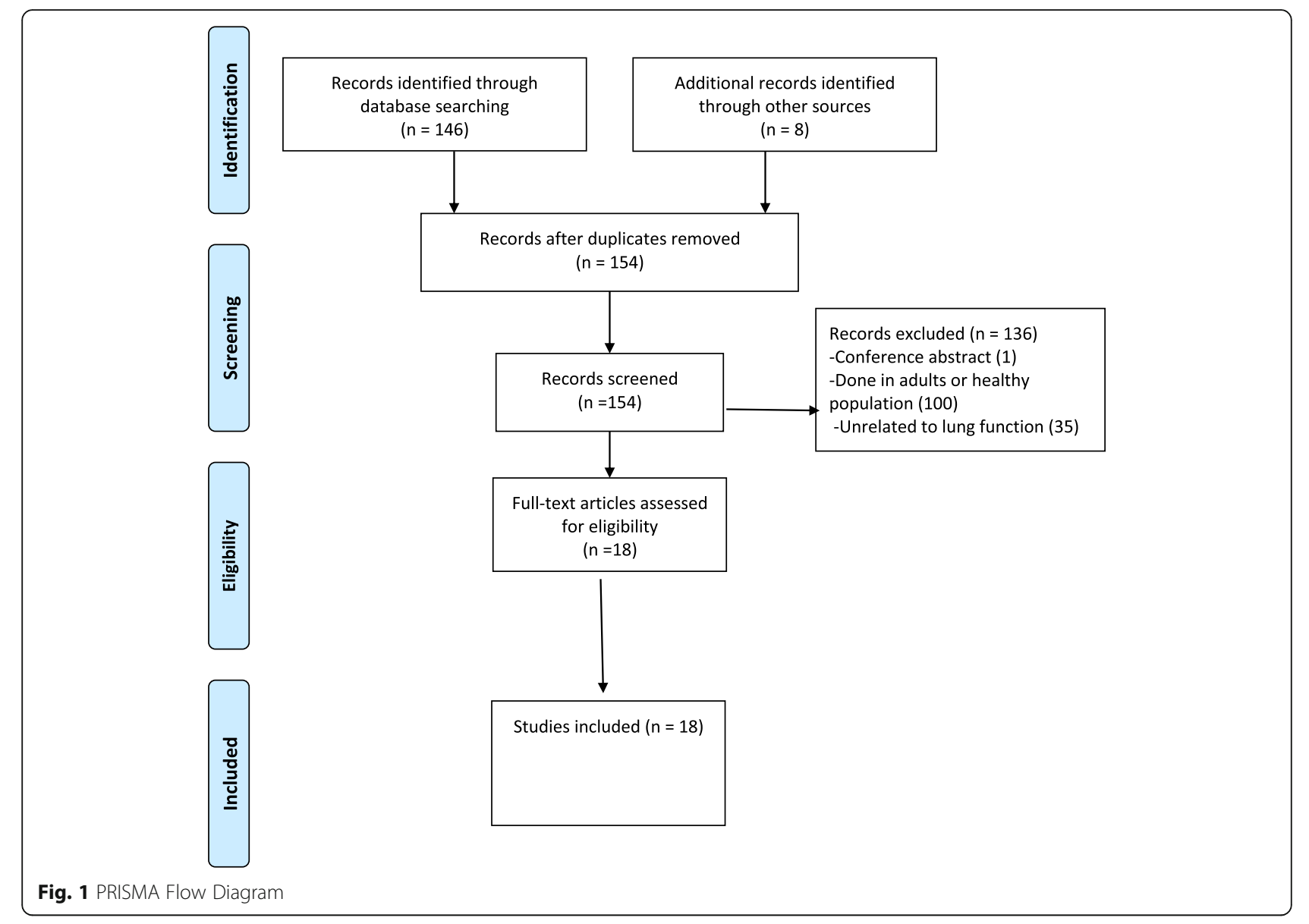

HIV-infected children with obstructive spirometry had positive bronchodilator responsiveness, while Githinji et al. [12] reported $15 \%$ of HIV-infected adolescents had bronchodilator responsiveness compared to $8 \%$ HIV-uninfected adolescents $(p=0.058)$. Mwalukomo et al. [13] reported $31.9 \%$ of the HIV-infected participants had bronchodilator responsiveness. Shearer et al. [20] reported similar rates of obstructive pattern spirometry between HIV-infected youth and HIV-exposed uninfected youth (22\% vs $21 \%)$, but a lower rate of bronchodilator responsiveness in the HIV-infected youth (17\% vs $9 \%, p=0.05)$.

Two studies reported diffusion tests (Table 2) that were found to be lower or impaired in the HIV-infected group compared to the uninfected. Airway obstruction and reduced diffusion capacity were consistent findings across age-groups from childhood $[10,11]$ to adolescence (Table 2).

Seven studies reported exercise tests for cardiopulmonary function status (6MWT or treadmill test) (Table 2), which showed that HIV-infected participants had functional aerobic impairment except for 1 study where no difference in distance walked or oxygen desaturation was reported after exertion (Table 2).
Determinants of lung function were reported in 4 studies $[5,6,12,13]$. History of previous lower respiratory tract infection or pulmonary TB was associated with reduced $\mathrm{FEV}_{1}$ and DLCO [12]. Cough $>1$ month was 2.9 times more likely to be associated with abnormal spirometry (95\%CI 1.21-7.10) [13]. Mosaic attenuation and extent of bronchiectasis were significantly associated with reduced $\mathrm{FEV}_{1},(r=-0.52$ and $r=-0.50, p<001$, respectively) [5].

One study reported MBW and FOT besides spirometry (Table 2), where HIV-infected adolescents had increased resistance, lower compliance, reduced functional residual capacity and increased lung clearance index compared to HIV-uninfected adolescents.

Two studies involved HIV-exposed uninfected children $[7,9]$, and 1 study had HIV-exposed uninfected youth as a comparator group [20]. Forced expiratory flow was about $20 \%$ less in the HIV-exposed group but this difference was not significant [21].

A summary of all studies included in this review is presented in Table 2. Overall, results showed that HIV-infected participants had reduced flow and volume and functional aerobic impairment on exercise, reduced 


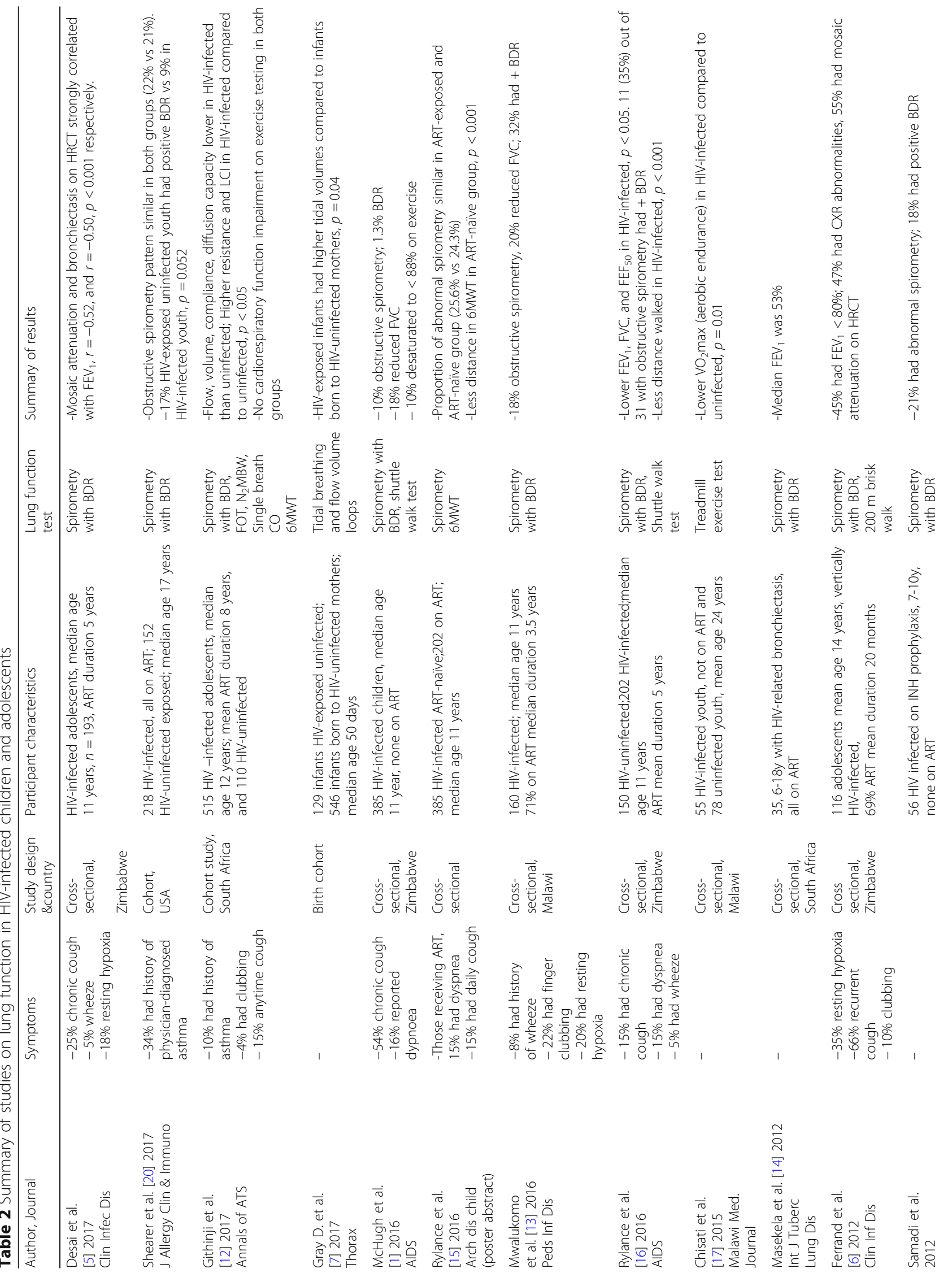




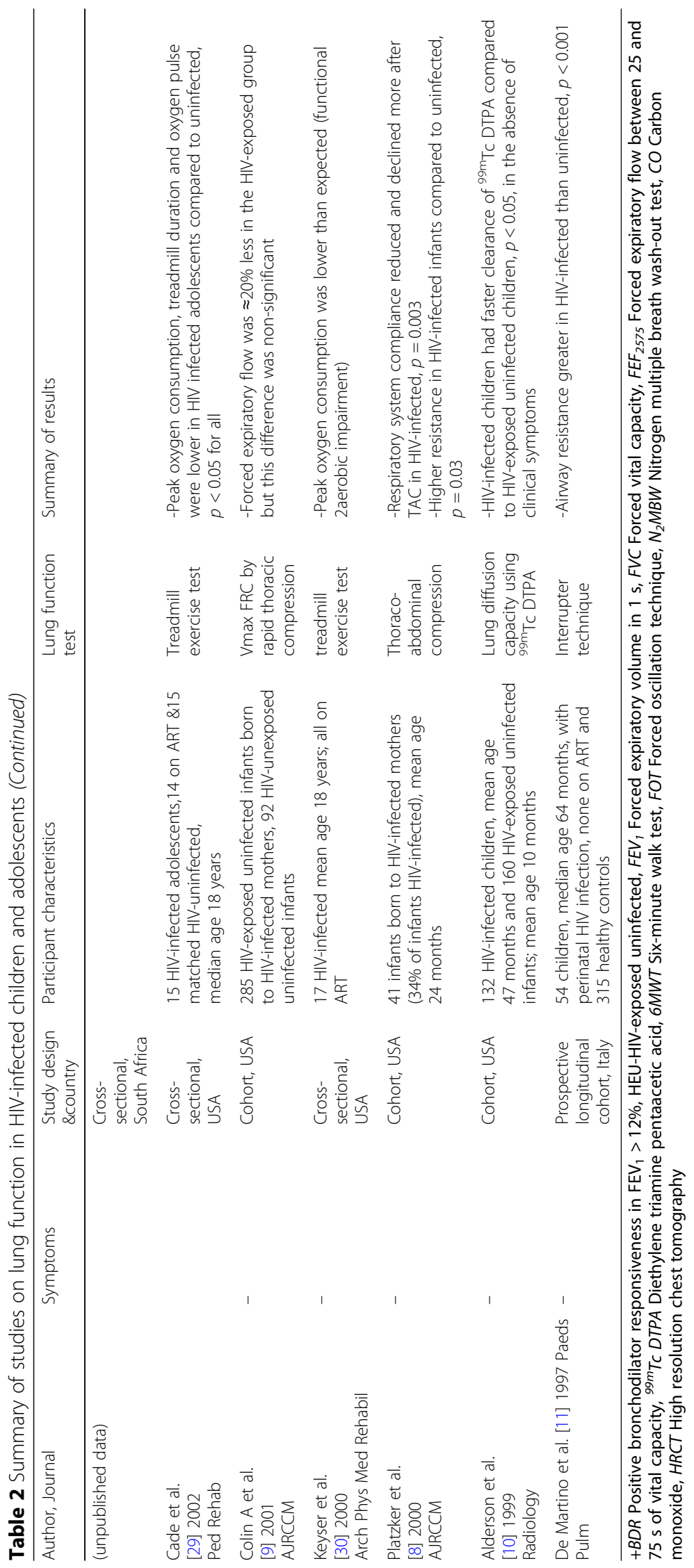


compliance, increased respiratory system resistance and reduced diffusion capacity compared to HIV-uninfected participants. Participants who had longer ART duration had less severe respiratory symptoms, less severe lower airway obstruction and no aerobic impairment.

\section{Discussion}

This review provides evidence of impairments in lung function in perinatally HIV-infected children and youth-predominantly irreversible lower airway obstruction, reduction in exercise tolerance and reduced diffusion capacity $[1,6,15,16]$. Fixed airflow obstruction was the most commonly reported finding, irrespective of ART status (Table 2).

Irreversible airway obstruction is likely to be a response to airway epithelium injury by opportunistic infections (OIs) or from HIV, repair of which can lead to proliferation of granulation tissue, fibrosis of airways and subsequent obliteration of the lumen [22]. Bronchiolitis obliterans, which may result in irreversible lower airway obstruction, has been reported as a predominant pathology, evidenced by radiological manifestation of mosaic attenuation on chest tomography in HIV-infected adolescents with delayed access to ART $[5,6]$. Systemic inflammatory markers have also been found to be increased in uncontrolled HIV or following repeated infections [23]. Lung infections like PCP [24] have been associated with increased metalloproteinases and chronic airflow obstruction in adults but none of the studies in this review reported prior PCP in participants.

ART has been reported in HIV-infected adults to be independently associated with irreversible airway obstruction but the mechanism remains unproven $[25,26]$. A direct effect of ART on inflammation in the lung and airways by reduction of peroxisome proliferator-activated receptor has been reported in adults [27]. Bronchodilator reversibility was reported to be present in $15-35 \%$ of participants. Despite the available evidence that irreversible airway obstruction is common in HIV-infected children, use of inhaled asthma medications has been reported to be widely used in HIV-infected children and adolescents [28]. Although bronchodilator reversibility was more common in HIV-exposed uninfected youths than in the HIV-infected youths, Shearer et al. [20] reported that self-reported asthma diagnosis was higher in HIV-infected youths than uninfected. This may be due to constellation of symptoms of asthma-like respiratory illness; for example, wheeze and cough in HIV-infected population and physician use of inhalers in the patients who present with such symptoms.

Differences in disease severity across study populations were more likely a result of varying duration of HIV infection and ART use. Those who had ART therapy for a duration of more than 7 years reported lower prevalence of respiratory symptoms [12] than those who initiated ART in later childhood $[1,6]$. Chronic lung diseases like bronchiectasis and bronchiolitis obliterans are likely to have occurred by the time of ART initiation, with most of these studies reporting higher prevalence of chronic cough and wheeze $[1,5,6]$.

Functional aerobic impairment was more common in HIV-infected participants than uninfected $[1,16,17,29$, 30]. Those on ART were reported to have done better on exertion than those not on ART [15]. The exercise intolerance may have been due to impaired ventilation-perfusion mechanics with possible heart dysfunction, though no study in this review reported cardiac function. The cardio-pulmonary function status results across studies were inconsistent due to patient selection differences, with Githinji et al. [12] reporting no significant difference in exercise status between the HIV-infected adolescents and the uninfected, and Chisati et al. [17] reporting low aerobic endurance in the HIV-infected group. These differences may be explained by differences in the cohorts and ART use; all children in the former cohort were stable on ART for a median duration of 8 years, whereas none of the youth in the latter study were on ART.

While adult studies $[25,31]$ have reported diffusion impairment as predominant lung function abnormality, diffusion impairment in HIV-infected children and adolescents has not been commonly investigated. However, HIV-infected adolescents on ART were reported to have lower diffusion capacity compared to HIV-uninfected adolescents [12]. This suggests that HIV or opportunistic infections may impair oxygen diffusion either by thickening of alveolar-capillary membrane due to interstitial inflammation or post-inflammation fibrosis, or due to reduced surface area for gas exchange, as seen in HIV-related bronchiectasis or bronchiolitis obliterans. Alveolar-capillary membrane integrity may be damaged by HIV and/or opportunistic infections well before the presence of clinical symptoms, as reported by Alderson et al. [10]. Emphysema, unlike in adults, was not documented as a common presentation in HIV-infected adolescents in Zimbabwe [5, 6]. Inflammation of the alveolar-capillary membrane by opportunistic infections like PCP and other acquired immunodeficiency syndrome (AIDS)-related complications has also been documented [31, 32]. Low diffusion capacity has been reported in adult patients who had previous TB in a South African cohort [33]. One study reported that pulmonary TB was associated with reduced DLCO in HIV-infected adolescents [12].

The evidence on the impact of HIV in utero is evolving, with only a few studies to date investigating HIV-exposed uninfected infants. These found no difference in spirometry pattern or forced expiratory flow on thoraco-abdominal compression between HIV-unexposed infants and HIV-exposed uninfected 
infants [9, 20]. Gray [7], however, reported increased tidal volumes in HIV-exposed uninfected infants compared to unexposed infants soon after birth.

Although accelerated lung function decline has been shown in HIV-infected adults [34, 35], published data on longitudinal lung function changes in HIV-infected children and adolescents are lacking. HIV has been reported to cause decline in lung function after controlling for other respiratory infections [31]. Bacterial pneumonia in HIV has been associated with permanent declines in $\mathrm{FEV}_{1}, \mathrm{FVC}, \mathrm{FEV}_{1} / \mathrm{FVC}$ and DLCO [36]. Pneumonia and pulmonary $\mathrm{TB}$ were reported to be more common in HIV-infected adolescents than uninfected in two of the studies $[12,16]$. A result of prenatal and postnatal origin of adult chronic obstructive airway disease as reported in several studies $[7,37,38]$ remains to be proven by longitudinal studies where these HIV-infected children and adolescents are followed to adulthood.

Limitations of this review include heterogeneity among studies and lack of reporting by some studies on the duration of ART. The studies were also carried out in different eras of PMTCT and ART roll-out, where ART was initiated at varying CD4 counts or clinical stages [39]. Description of obstructive and restrictive spirometry patterns was not uniform across studies with most studies reporting reduced FVC as a spirometry pattern and 1 study also including $\mathrm{FEF}_{25-75}$ in the definition of obstructive spirometry. Determinants of lung function were also not widely reported. Almost all studies were cross sectional with very limited data on longitudinal changes in lung function over time.

\section{Conclusion}

There is increasing evidence that HIV-infected children and adolescents have high prevalence of lung function impairment, predominantly irreversible lower airway obstruction and reduced aerobic function. Lung function impairment was milder in cohorts of adolescents/children who had had earlier access to ART. Lung function impairment starts early in life in the absence of ART, as evidenced by the papers published in the pre-ART era. Achievement of viral suppression through ART may preserve lung function, though at a lower level compared to HIV-uninfected individuals $[1,12,20,34]$.

\section{Future directions}

There is a need for longitudinal studies on lung function in HIV-infected children and adolescents in the post-ART era into adulthood, as there is increasing evidence that chronic obstructive pulmonary disease has its origins in early life [38]. There is also need for more studies comparing lung function among HIV-infected, HIV-exposed uninfected and HIV-uninfected children and adolescents, to provide evidence on how exposure to maternal virus in utero may affect lung function and how early intervention with ART in HIV-infected pregnant mothers may help to preserve lung function in infants and children.

\section{Abbreviations \\ 6MWT: Six-minute-walk test; ART: Antiretroviral therapy; BDR: Bronchodilator responsiveness; CLD: Chronic lung disease; DLCO: Single breath diffusion test for carbon monoxide; FOT: Forced oscillation technique; MBW: Nitrogen multiple-breath washout test; PCP: Pneumocystis jirovecii pneumonia; PMTCT: Prevention of mother-to-child transmission}

\section{Acknowledgements}

Dilshaad Brey, University of Cape Town, South Africa, for expert assistance on searching electronic databases.

\section{Funding}

African Partnership for Chronic Diseases and South Africa Medical Research Council.

Availability of data and materials

Data sharing not applicable to this article as no datasets were generated during the current study.

\section{Authors' contributions}

LG: abstracted data and wrote the manuscript. HZ: initial idea conception and wrote manuscript. DG: wrote manuscript. All authors read and approved the final manuscript.

Ethics approval and consent to participate

Obtained from University of Cape Town, Human Research Ethics Committee Ref: 018/2016.

Consent for publication

Not applicable.

Competing interests

Authors declare that they have no competing interests.

\section{Publisher's Note}

Springer Nature remains neutral with regard to jurisdictional claims in published maps and institutional affiliations.

Received: 26 December 2017 Accepted: 13 June 2018

Published online: 25 June 2018

\section{References}

1. McHugh G, Rylance J, Mujuru H, Nathoo K, Chonzi P, Dauya E, Bandason T, Simms V, Kranzer K, Ferrand RA. Chronic morbidity among older children and adolescents at diagnosis of HIV infection. Jaids-J Acquir Immune Defic Syndr. 2016;73:275-81.

2. Ue: UNAIDS 2016 estimates. http://aidsinfo.unaids.org/.

3. UNAIDS. Fact sheet July 2017. 2017. Available at http://www.unaids.org/en/ resources/fact-sheet.

4. Pitcher R, Beningfield S, Zar H. Chest radiographic features of lymphocytic interstitial pneumonitis in HIV-infected children. Clin Radiol. 2010;65:150-4

5. Desai SR, Nair A, Rylance J, Mujuru H, Nathoo K, McHugh G, Majonga E, Metcalfe J, Kranzer K, Ferrand RA. Human Immunodeficiency VirusAssociated Chronic Lung Disease in Children and Adolescents in Zimbabwe: Chest Radiographic and High-Resolution Computed Tomographic Findings. Clin Infect Dis. 2018;66:274-81.

6. Ferrand RA, Desai SR, Hopkins C, Elston CM, Copley SJ, Nathoo K, Ndhlovu CE, Munyati S, Barker RD, Miller RF. Chronic lung disease in adolescents with delayed diagnosis of vertically acquired HIV infection. Clin Infect Dis. 2012; $55: 145-52$.

7. Gray D, Willemse L, Visagie A, Czovek D, Nduru P, Vanker A, Stein DJ, Koen $N$, Sly PD, Hantos Z, et al. Determinants of early-life lung function in African infants. Thorax. 2017;72:445-50.

8. Platzker AC, Colin AA, Chen XC, Hiatt P, Hunter J, Koumbourlis AC, Schluchter MD, Ting A, Wohl ME. Thoracoabdominal compression and 
respiratory system compliance in HIV-infected infants. Am J Respir Crit Care Med. 2000;161:1567-71.

9. Colin AA, Sunil Rao J, Chen XC, Hunter JM, Hanrahan J, Hiatt P, Kattan M, Koumbourlis A, Mellins RB, Peavy HH, et al. Forced expiratory flow in uninfected infants and children born to HIV-infected mothers. Am J Respir Crit Care Med. 2001;163:865-73.

10. Alderson PO, Chen DC, Fleishman MJ, Hoh CK, Kim CK, Lee WW, Mellins RB, Miller $\mathrm{JH}$, Moore WH, Peavy HH. Radioaerosol Scintigraphy in infants and children born to mothers with HIV disease. Radiology. 1999;210:815-22.

11. De Martino M, Veneruso G, Gabiano C, Frongia G, Tulisso S, Lombardi E, Tovo PA, Galli L, Vierucci A. Airway resistance and spirometry in children with perinatally acquired human immunodeficiency virus-type 1 infection. Pediatr Pulmonol. 1997;24:406-14.

12. Githinji LN, Gray DM, Hlengwa S, Myer L, Zar HJ. Lung function in south African adolescents infected perinatally with HIV and treated long-term with antiretroviral therapy. Ann Am Thorac Soc. 2017;14:722-9.

13. Mwalukomo T, Rylance SJ, Webb EL, Anderson S, O'Hare B, van Oosterhout $\mathrm{JJ}$, Ferrand RA, Corbett EL, Rylance J. Clinical characteristics and lung function in older children vertically infected with human immunodeficiency virus in Malawi. J Pediatric Infect Dis Soc. 2016;5:161-9.

14. Masekela R, Anderson R, Moodley T, Kitchin OP, Risenga SM, Becker PJ Green RJ. HIV-related bronchiectasis in children: an emerging spectre in high tuberculosis burden areas. Int J Tuberc Lung Dis. 2012;16:114-9.

15. Rylance S, Rylance J, McHugh G, Mujuru H, Munyati S, Bandason T, Metcalfe J, Kranzer K, Ferrand R. G276 (P) chronic respiratory morbidity among HIVinfected children in Zimbabwe; a comparison of ART naïve and treated cohorts. Arch Dis Child. 2016;101:A156-7.

16. Rylance J, Mchugh G, Metcalfe J, Mujuru H, Nathoo K, Wilmore S, RowlandJones S, Majonga E, Kranzer K, Ferrand RA. Chronic lung disease in HIV-infected children established on antiretroviral therapy. AIDS. 2016;30:2795-803.

17. Chisati EM, Vasseljen O. Aerobic endurance in HIV-positive young adults and HIV-negative controls in Malawi. Malawi Med J. 2015;27:5.

18. Miller MR, Hankinson J, Brusasco V, Burgos F, Casaburi R, Coates A, Crapo R, Enright P, Van der Grinten C, Gustafsson P. Standardisation of spirometry. Eur Respir J. 2005;26:319-38.

19. Quanjer PH, Stanojevic S, Cole TJ, Baur X, Hall GL, Culver BH, Enright PL, Hankinson JL, Ip MS, Zheng J. Multi-ethnic reference values for spirometry for the 3-95-yr age range: the global lung function 2012 equations. Eur Respir J. 2012;40:1324-43.

20. Shearer WT, Jacobson DL, Yu W, Siberry GK, Purswani M, Siminski S, Butler L, Leister E, Scott G, Van Dyke RB. Long-term pulmonary complications in perinatally HIV-infected youth. J Allergy Clin Immunol. 2017;140:1101-11. e1107.

21. Colin AA, Sunil Rao J, Chen XC, Hunter JM, Hanrahan J, Hiatt P, Kattan M, Koumbourlis A, Mellins RB, Peavy HH. Forced expiratory flow in uninfected infants and children born to HIV-infected mothers. Am J Respir Crit Care Med. 2001;163:865-73.

22. Kurland G, Michelson P. Bronchiolitis obliterans in children. Pediatr Pulmonol. 2005;39:193-208.

23. Gingo MR, Wenzel SE, Steele C, Kessinger CJ, Lucht L, Lawther T, Busch M, Hillenbrand ME, Weinman R, Slivka WA. Asthma diagnosis and airway bronchodilator response in HIV-infected patients. J Allergy Clin Immunol. 2012;129:708-714. e708.

24. Morris A, Alexander T, Radhi S, Lucht L, Sciurba FC, Kolls JK, Srivastava R, Steele C, Norris KA. Airway obstruction is increased in pneumocystiscolonized human immunodeficiency virus-infected outpatients. J Clin Microbiol. 2009;47:3773-6.

25. Gingo MR, George MP, Kessinger CJ, Lucht L, Rissler B, Weinman R, Slivka WA, McMahon DK, Wenzel SE, Sciurba FC. Pulmonary function abnormalities in HIV-infected patients during the current antiretroviral therapy era. Am J Respir Crit Care Med. 2010;182:790-6.

26. George MP, Kannass M, Huang L, Sciurba FC, Morris A. Respiratory symptoms and airway obstruction in HIV-infected subjects in the HAART era. PLoS One. 2009:4:e6328.

27. Mallon PWG, Unemori P, Sedwell R, Morey A, Rafferty M, William K, Chisholm D, Samaras K, Emery S, Kelleher A, et al. In vivo, nucleoside reverse-transcriptase inhibitors Alter expression of both mitochondrial and lipid metabolism genes in the absence of depletion of mitochondrial DNA. J Infect Dis. 2005;191:1686-96.

28. Siberry GK, Leister E, Jacobson DL, Foster SB, Seage GR, Lipshultz SE, Paul ME, Purswani M, Colin AA, Scott G. Increased risk of asthma and atopic dermatitis in perinatally HIV-infected children and adolescents. Clin Immunol. 2012;142:201-8.

29. Cade WT, Peralta L, Keyser RE. Aerobic capacity in late adolescents infected with HIV and controls. Pediatr Rehabil. 2002:5:161-9.

30. Keyser RE, Peralta L, Cade WT, Miller S, Anixt J. Functional aerobic impairment in adolescents seropositive for HIV: a quasiexperimental analysis. Arch Phys Med Rehabil. 2000;81:1479-84.

31. Diaz PT, King MA, Pacht ER, Wewers MD, GADEK JE, Neal D, Nagaraja HN, Drake J, Clanton TL. The pathophysiology of pulmonary diffusion impairment in human immunodeficiency virus infection. Am J Respir Crit Care Med. 1999;160:272-7.

32. Crothers K, McGinnis K, Kleerup E, Wongtrakool C, Hoo GS, Kim J, Sharafkhaneh A, Huang L, Luo Z, Thompson B. HIV infection is associated with reduced pulmonary diffusing capacity. J Acquir Immune Defic Syndr (1999). 2013:64:271-8

33. Bateman E, Rom W, Dheda K, van Zyl-Smit R, Weiden M, Dawson R, Calligaro $G$. Respiratory symptoms and pulmonary function abnormalities in Hiv-infected patients on antiretroviral therapy in a high tuberculosis burden country. Am J Respir Crit Care Med. 2011;183:A6262.

34. Kristoffersen US, Lebech AM, Mortensen J, Gerstoft J, Gutte H, Kjaer A. Changes in lung function of HIV-infected patients: a 4.5-year follow-up study. Clin Physiol Funct Imaging. 2012;32:288-95.

35. Drummond MB, Merlo CA, Astemborski J, Marshall MM, Kisalu A, McDyer JF, Mehta SH, Brown RH, Wise RA, Kirk GD. The effect of HIV infection on longitudinal lung function decline among injection drug users: a prospective cohort. Aids. 2013;27:1303-11.

36. Morris AM, Huang L, Bacchetti P, Turner J, Hopewell PC, Wallace JM, Kvale PA, Rosen MJ, Glassroth J, Reichman LB. Permanent declines in pulmonary function following pneumonia in human immunodeficiency virus-infected persons. Am J Respir Crit Care Med. 2000;162:612-6.

37. Postma DS, Bush A, van den Berge M. Risk factors and early origins of chronic obstructive pulmonary disease. Lancet. 2015;385:899-909.

38. Sly PD, Bush A. From the cradle to the grave: the early-life origins of chronic obstructive pulmonary disease. Am Thoracic Soc. 2016;

39. Organization WH: Consolidated guidelines on HIV prevention, diagnosis, treatment and care for key populations. 2016.

\section{Ready to submit your research? Choose BMC and benefit from:}

- fast, convenient online submission

- thorough peer review by experienced researchers in your field

- rapid publication on acceptance

- support for research data, including large and complex data types

- gold Open Access which fosters wider collaboration and increased citations

- maximum visibility for your research: over $100 \mathrm{M}$ website views per year

At BMC, research is always in progress.

Learn more biomedcentral.com/submissions 